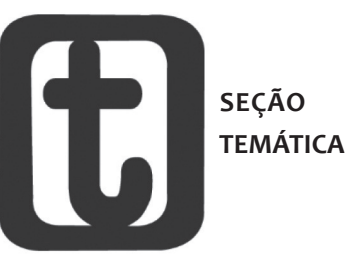




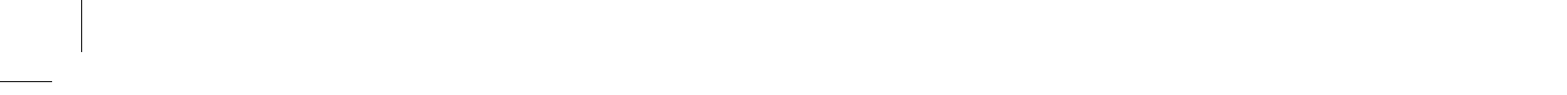




\title{
田
}

\section{SOBRE O CONCEITO DE CAPITAL FINANCEIRO}

\author{
ABOUT THE CONCEPT OF FINANCIAL CAPITAL
}

\author{
Mauricio de Souza Sabadini'
}

\section{RESUMO}

A obra O Capital financeiro (1910) de Rudolf Hilferding influenciou autores clássicos e contemporâneos acerca de várias temáticas na Economia e nas Ciências Sociais. Vivemos em um período histórico onde os entrelaçamentos entre a produção e as finanças estão cada vez mais fortes e complexos e onde os movimentos financeiros especulativos interferem fortemente na dinâmica da acumulação. Historicamente, as novas formas de poder econômico, a ascensão de novos atores financeiros, a forma de apropriação do excedente econômico, o esgotamento da livre-concorrência, o aumento da concentração de capital, requerem uma (re) leitura e um "novo olhar" interpretativo sobre contribuições de autores clássicos como Hilferding. Para tentar captar algumas dessas contribuições à luz de nossa realidade, este artigo tem por objetivo fazer uma (re) leitura do conceito de Capital financeiro.

Palavras-chave: Capital financeiro. Hilferding. finanças, capital fictício

\section{ABSTRACT}

The work The Finance Capital (1910) of Rudolf Hilferding influenced classical and contemporary authors about various topics in Economics. We live in a historical period where the connections between production and finance are increasingly powerful and complex, and where the speculative financial movements directly interfere heavily in the dynamics of accumulation. Historically the new forms of economic power, the rise of new financial actors, the form of appropriation of the economic surplus, the depletion of free compe-

1 Doutorado em Economia pela Université Paris 1 Panthéon-Sorbonne. Professor do Departamento de Economia e do Programa de Pós-Graduação em Política Social (PPGPS) da Universidade Federal do Espírito Santo (UFES). Tutor do grupo PET-Economia/Ufes (Sesu-MEC). 


\section{temporollis}

tition, increased concentration of capital, requires a (re) reading and a "new look" interpretive about contributions from classical authors such as Hilferding. To try to capture some of these contributions according to our reality, this article has the purpose to make a (re) reading of the concept of Finance capital.

Keywords: Financial capital. Hilferding. Finance. fictitious capital

Submetido: 01/09/2015.

Aceito: 26/11/2015.

\section{INTRODUÇÃO}

O fundamento e a origem deste artigo encontram-se na realização de um esforço maior que procura avaliar as contribuições teóricas de Rudolf Hilferding em sua obra O Capital financeiro (1910) observando, sobretudo, a dinâmica financeira e especulativa do capitalismo, bem como suas relações com a esfera real, produtiva.

Se a obra de Hilferding talvez não tenha recebido tanta atenção no meio acadêmico, pelo menos em relação à bibliografia mais recente, é verdade que a temática influenciou análises de autores renomados como Lênin, Böehm-Bawerk, Harvey, Schumpeter, Sweezy, Rosa Luxemburgo, Suzanne de Brunhoff, Marshall, Bukharin, apenas para citar alguns deles, contribuindo para o debate acerca da constituição e compreensão do capitalismo ao longo do século XX. Após mais de 100 anos de sua publicação, essa influência e a presença de conceitos chaves elaborados pelo referido autor ainda marcam profundamente a literatura acadêmica e não acadêmica.

Mas, nas últimas décadas do século XX, com o fim do acordo de Bretton Woods e a consequente desregulamentação da esfera financeira mundial, a discussão sobre o capital financeiro parece que adquiriu um sentido se não errôneo ao menos insuficiente, pelo menos para se entender a dinâmica do capitalismo contemporâneo.

Os primeiros anos após a publicação da obra de Hilferding foram representativos em termos de acontecimentos históricos que marcaram a humanidade. A eclosão da $1^{a}$ grande Guerra Mundial, em 1914, a Revolução Russa, em 1917, a grande Crise de 1929 e a $2^{\text {a Guerra }}$ Mundial, em 1939, foram alguns que mudaram a trajetória geopolítica global trazendo à cena o despertar da hegemonia norte-americana e o remodelamento das relações entre as frações do capital representativas da esfera produtiva e financeira.

Na produção, o crescimento e o consequente amadurecimen- 


\section{tempordilis}

to das relações corporativas das grandes unidades industriais criaram uma estrutura diferenciada em vários setores da atividade econômica, num contexto monopolista. Ao mesmo tempo, na esfera da circulação, o capital financeiro continuava sua função de financiamento da atividade produtiva, tendo também ao seu lado o caráter intrínseco, mas ainda não determinante, da especulação financeira.

Se a etapa capitalista concorrencial dava lugar gradativamente ao capitalismo monopolista, começava também a emergir uma estrutura técnica mais profissionalizada em relação aos antigos proprietários, que também eram gerentes em suas unidades industriais, tanto na gestão produtiva quanto na financeira. É o despertar das Grandes Empresas (GE) que acompanhava as transformações de um capitalismo em consolidação das forças produtivas.

Foi em meio a algumas dessas mudanças que Hilferding esteve à frente do Ministério das Finanças da Alemanha em períodos extremamente turbulentos como foram os anos de 1923 e 1929, levando alguns autores como Marshall (2011) a destacar a sua influência como homem político². Ao mesmo tempo, a publicação de "O Capital financeiro" de certa forma revolucionou a forma de pensar e utilizar o método marxista para a compreensão das fases do ciclo do capital.

Muitas das ideias de Hilferding continuam a ser usadas na literatura especializada. Em meio a um contexto de crise capitalista e expansão financeira e produtiva do capital, vivemos um período histórico no qual os entrelaçamentos entre a produção e a finança estão cada vez mais fortes e complexos e em que os movimentos financeiros especulativos interferem diretamente na condução da política e da economia dos países desenvolvidos e subdesenvolvidos.

As novas formas de poder econômico, a ascensão de novos atores financeiros (fundos de pensão, fundos especulativos, seguradoras, etc.), a forma de apropriação do excedente econômico, o esgotamento da livre-concorrência, a implantação de novas técnicas de gestão e inovação, o aumento da escala produtiva e da concentração industrial, as crises capitalistas recorrentes que se manifestam na esfera financeira, dentre outros, requerem uma (re) leitura e um "novo olhar" interpretativo sobre contribuições de autores clássicos como Hilferding, por exemplo.

2 Um excelente artigo que mostra a trajetória política e intelectual de Hilferding é o de Smaldone (1988). 


\section{temporollis}

Muito criticado por sua visão reformista relacionada ao chamado "capitalismo organizado", Hilferding desenvolveu temas que consideramos fundamentais para a análise do capitalismo contemporâneo e que dá nome aos títulos e capítulos da primeira, segunda e terceira partes de sua obra: o tratamento do dinheiro, do crédito, da Sociedade Anônima (SA), dos dividendos e do lucro de fundador, da bolsa de valores e a especulação, do capital financeiro e, finalmente, do capital fictício.

Naturalmente, todos estes assuntos fogem ao escopo de nossa análise. Discutiremos aqui somente um aspecto: o conceito de capital financeiro. Por isso, este artigo tem por objetivo principal fazer uma (re) leitura do conceito de capital financeiro em Hilferding.

\section{Algumas visões sobre o conceito de capital financeiro}

O debate travado na primeira metade do século XX em torno da noção do capital financeiro rendeu importantes reflexões acerca das mutações do capitalismo. Todos influenciados por Hilferding, alguns autores, citados anteriormente, enriqueceram a discussão na tentativa de entender as novas formas imperialistas e suas estratégias de acumulação, agora vinculadas estreitamente à expansão financeira do capital.

Sem querer propor uma tipologia das diferentes visões e interpretações que permeiam o tema em questão, identificamos três leituras que analisam o conceito de capital financeiro. Apesar de apresentadas em separado acreditamos que elas estão interligadas, já que adotam de uma forma ou de outra os princípios básicos descritos por Hilferding. Vejamos.

A "visão tradicional" adotada pela quase totalidade dos autores segue o clássico conceito de capital financeiro a partir da seguinte descrição de Hilferding (1985, p. 219):

A dependência da indústria com relação aos bancos é, portanto, consequência das relações de propriedade. Uma porção cada vez maior do capital da indústria não pertence aos industriais que o aplicam. Dispõem do capital somente mediante o banco, que perante eles representa o proprietário. Por outro lado, o banco deve

3 Ver Pierre (2010, p. 41). 


\section{tempordils}

imobilizar uma parte cada vez maior de seus capitais. Torna-se, assim, em proporções cada vez maiores, um capitalista industrial. Chamo de capital financeiro o capital bancário, portanto o capital em forma de dinheiro que, desse modo, é na realidade transformado em capital industrial. Mantém sempre a forma de dinheiro ante os proprietários, é aplicado por eles em forma de capital monetário - de capital rendoso [portador de juros] - e sempre pode ser retirado por eles em forma de dinheiro. Mas, na verdade, a maior parte do capital investido dessa forma nos bancos é transformado em capital industrial, produtivo (meios de produção e força de trabalho) e imobilizado no processo de produção. Uma parte cada vez maior do capital empregado na indústria é capital financeiro, capital à disposição dos bancos e, [empregado] pelos industriais.

Alguns pontos desta definição merecem aqui comentários. Em primeiro lugar, notamos a clara utilização da palavra "dependência" para caracterizar a relação entre a atividade industrial e a influência direta dos bancos, toda ela capitaneada pelas mutações nas relações de propriedade com o surgimento das sociedades anônimas e a importância da bolsa de valores para as transações dos títulos de propriedade (ações). Os bancos, na qualidade de credores, controlam o dinheiro de crédito do sistema capitalista. Em segundo lugar, as afirmações acima indicam a transformação do capital bancário em capital produtivo. Ou seja, a relação de financiamento acontece diretamente dos bancos para a empresa e, em seguida, o controle monetário pelas instituições bancárias lhe dá direito sobre a propriedade das ações, configurando uma nova relação que substitui a posse dos ativos fixos da planta industrial. A associação entre as sociedades anônimas e o movimento de compra e venda dos títulos de propriedade (ações) nas bolsas de valores fornece a base para se entender a expansão das grandes empresas, bem como suas fusões e aquisições.

O financiamento bancário do capital fixo, emergindo ao mesmo tempo com a transformação da propriedade familiar para as sociedades anônimas como forma dominante da organização capitalista, fecha um círculo de dominação da empresa pelo capital bancário, implicando no posicionamento dos banqueiros como proprietários acionistas diante dos empresários industriais.

Hilferding (1985, p. 283), já no primeiro parágrafo do capítulo 


\section{temporollis}

XXI, conclui seu conceito reafirmando alguns de seus princípios, como a dominação bancária e a junção monopolista:

O capital financeiro significa a uniformização do capital. Os setores do capital industrial, comercial e bancário, antes separados, encontram-se agora sob a direção comum das altas finanças, na qual estão reunidos, em estreita união pessoal, os senhores da indústria e dos bancos.

No que tange a monopolização, Delilez (1970) dá destaque ao "monopólio industrial", entendido genericamente como a concentração de capitais na produção (distribuição, estocagem, subcontratações), e ao "monopólio bancário" que controla a formação de capitais (centralização dos lucros, arrecadação de depósitos e poupança), para o entendimento do capital financeiro. Para ele,

[...] o capital financeiro se define como o sistema de inter-relações e de interdependência entre essas duas categorias. Ele tende a coordenar e a integrar os dois movimentos. Mas o que lhe confere suas características próprias é que em seu seio se manifestam os desajustamentos e as divergências entre essas duas categorias (DELILEZ, 1970, p. 808).

As palavras deste autor confirmam o que estamos aqui chamando de visão tradicional, em que a associação e dependência da indústria em relação aos bancos tornam-se centrais, transformando radicalmente a propriedade capitalista pela emergência da sociedade por ações e pela extinção da livre-concorrência. E os autores, ao utilizarem este conceito de Hilferding, adotam esta perspectiva de relação entre esfera produtiva e financeira.

Ao mesmo tempo, encontramos vários trabalhos com uma "visão intermediária" que, por um lado, aceitam e utilizam o conceito tradicional e, por outro, criticam aspectos desenvolvidos pelo próprio Hilferding. Sweezy (1983), por exemplo, utiliza a definição tradicional de Hilferding adotando a perspectiva de fusão dos bancos com a indústria, mas recusa a tese da tendência histórica de dominação do capital bancário. Para ele o capital bancário só pode exercer o poder de dominação em uma fase transitória e não permanente do desenvolvimento capitalista.

É certo que durante o período do próprio movimento 


\section{tempordils}

de combinação, quando as sociedades anônimas e as fusões estão em processo de formação, os bancos desfrutam uma posição estratégica que lhes permite influir sobre áreas-chaves do sistema produtivo. 0 processo de combinação, porém, não pode continuar indefinidamente [...]. O capital bancário, que já teve seus dias de glória, volta novamente a uma posição subsidiária em relação ao capital industrial, restabelecendo dessa forma a relação que existia antes do movimento de combinação (SWEEZY, 1983, p. 205-206).

Neste sentido, para Sweezy a base é o capital produtivo e não o capital bancário. Posições intermediárias como esta são adotadas por outros autores, como Lênin. Ao tratar do imperialismo, Lênin afirma que o mesmo "[...] é a fase monopolista do capitalismo. Esta definição englobaria o essencial, porque, por um lado, o capital financeiro é o resultado da fusão do capital de alguns grandes bancos monopolistas com o capital de grupos monopolistas [...]" (LÊNIN, 1979, p. 87-88). Apesar de fazer a crítica a Hilferding, tratando-o de "[...] antigo marxista, hoje companheiro de armas de Kautsky e um dos principais representantes da política burguesa, reformista", Lênin adota os princípios gerais de seu conceito de capital financeiro, sugerindo que uma das características do imperialismo é a "[...] fusão do capital bancário e do capital industrial, e criação, com base nesse 'capital financeiro', de uma oligarquia financeira" (p. 88). Por outro lado, afirma que "[...] esta definição é incompleta, na medida em que silencia um fato da mais alta importância, a saber, a concentração da produção e do capital, a tal ponto desenvolvida que ela dá e já deu origem ao monopólio" (LÊNIN, 1979, p. 46).

Apesar dessas ponderações, a influência de Hilferding e a disseminação de seu conceito estão associadas a transformações que "[...] deste modo, o séc. XX marca o ponto de partida de viragem em que o antigo capitalismo deu lugar ao novo, em que o domínio do capital financeiro substitui o domínio do capital em geral." (LÊNIN, 1979, p. 45). Como em Hilferding, a indicação da tomada do poder pelos capitalistas financeiros é muito clara também em Lênin, unificando e dominando o capitalismo de então pelas novas formas financeiras.

Evidentemente, Lênin utilizou certas categorias de Hilferding e desenvolveu outras, como a análise da divisão territorial e suas estratégias de acumulação, a incorporação da oligarquia financeira, termo presente em "O Capital”, e a importância da exportação de capitais e 


\section{temporollis}

da união de empresas monopolistas que partilharam o mundo. Assim, suas diferenças também estão postas. Harvey (1990) conclui dizendo que Lênin difere de Hilferding na medida em que aceita a identificação da esfera financeira com o capital nacional no caso das principais potências imperialistas, assumindo uma concepção supranacional do circuito financeiro na sua análise do capitalismo mundial.

Da mesma forma, Palloix (2006, p. 281) afirma, ao se utilizar do conceito tradicional, que "[...] o capital financeiro é o momento pelo qual o capital bancário torna-se também capital industrial no curso do ciclo funcional do capital que é, ao longo do canal conceitual, o capital fictício". Nota-se que o autor faz uso e referência da associação do capital produtivo e bancário, e, ao mesmo tempo, destaca o capital fictício como elo conceitual da análise, algo que ainda não tinha aparecido mais diretamente entre os autores citados.

Lapavitsas (2008), citado por Hilferding, afirma que o conceito de capital financeiro "[...] representa uma mudança de época induzida pela alteração na relação entre capital produtivo e bancário" (p. 31). Prossegue dizendo que como a escala de produção cresce, empresas industriais e bancos tornam-se cada vez mais concentrados e formam cartéis monopolistas. Além disso, as firmas precisam de volume cada vez maior de investimento em capital fixo, o que as tornam muito dependentes dos bancos para a aquisição do crédito. O resultado é a criação do capital financeiro, um amálgama do capital produtivo e bancário com os bancos em ascensão, que restringe a concorrência e domina a economia para seus interesses.

Quando analisa a dinâmica financeira atual do capitalismo, o autor sugere que não é possível retornar ao capital financeiro de Hilferding. Para ele, os bancos e as grandes empresas industriais ou comerciais não se fundiram ao longo das últimas décadas e não existem provas de que os bancos detêm um controle superior das relações com a indústria. Pelo contrário, as grandes companhias tornaram-se mais distantes dos bancos e o sistema financeiro tornou-se mais autônomo.

Parece-nos que Lapavitsas já está aqui num momento avançado de interpretação do conceito de capital financeiro, relacionando-o a fase atual do capitalismo. Por isso, ele o nega quando o utiliza para interpretar o capitalismo contemporâneo e sugere outro conceito, o de "financeirização", com maior autonomia para a parcela financeira. 
Finalmente, a "visão alternativa" que avança na temática. Até o presente, nossas leituras identificaram dois autores que trazem algo diferenciado: Pinto (1994, 1997) e Guillén (2011a, 2011b)ª . Façamos uma breve síntese.

Pinto (1994, 1997) apresenta uma das leituras mais originais da obra de Hilferding. Correndo o risco de resumi-la indevidamente, seus argumentos centrais baseiam-se no fato de que a pertinência do conceito de capital financeiro em Hilferding deve-se pautar na observação da transição vivida pelo capitalismo de fim do século XIX para uma fase de feição predominantemente financeira. Ou seja, o capitalismo tradicional, de base industrial e padrão familiar, dá lugar ao capitalismo financeiro, que rompe com as barreiras da acumulação e intensifica a racionalidade maximizadora e gerencial.

Neste sentido, o capitalismo financeiro impôs novos parâmetros à dinâmica da acumulação privada, já que a materialização da riqueza sob a forma de títulos altera os critérios de alocação dos recursos, diferente da fase industrial. No processo de transformação da forma de riqueza, do controle da propriedade sob a forma de ativos fixos para as ações, é a posse e a manipulação dos títulos que permitem acesso aos direitos de gestão sobre a atividade produtiva. Então, para o autor, a riqueza privada se dissocia dos meios de produção.

A partir destes elementos, Pinto (1994) sugere que o conceito de capital financeiro foi utilizado ao longo dos anos de maneira superficial, já que "[...] a noção de capital financeiro foi descaracterizada de seu sentido mais abrangente e reduzida a uma simples expressão do conjunto de recursos empregado pelo setor financeiro" (p. 39). Referindo-se a Hobson e aos autores marxistas que enfatizam o poder de dominação da indústria pelos bancos, a visão tradicional, Pinto (1994, p. 65), sugere que

[...] não faz sentido em falar-se em dominação onde o capital bancário é compreendido como uma parte constitutiva do capital industrial. [...] o contraponto para uma possível proeminência do segmento financeiro seria a sua dimensão setorial. Ou seja, a submissão das atividades da indústria ou do comércio de mercadorias ao setor

4 Lapavitsas também avança ao fazer os comentários acima. Mas, parece-nos que, diferente da visão alternativa, ele não identifica "no conceito de capital financeiro de Hilferding" a possibilidade da dinâmica especulativa do capital. 


\section{temporollis}

de comércio de dinheiro. Supondo-se que a ideia de dominação tenha expressão econômica e possa, portanto, ser traduzida por uma rentabilidade superior à vigente nos setores subordinados, seria necessário superar mais uma objeção de caráter geral. (Grifo do autor).

Conforme Pinto, no mundo contemporâneo a hipótese mais sensata e realista é a de que as sociedades anônimas aglutinam e organizam os ativos produtivos e bancários em várias frentes de atividade, se estendendo às atividades financeiras e não financeiras. Lembra o autor que mesmo a concessão e controle do crédito pelos bancos não sinaliza uma exclusividade das instituições bancárias. Portanto:

[...] ao se definir esta fase como tendo sido a de consagração do 'domínio dos banqueiros/financistas' passa-se ao largo do que há de mais importante na transformação que se processou: a crescente flexibilidade (mobilidade e divisibilidade) que a riqueza privada passou a assumir. (PINTO, 1994, p. 70).

Tentando retirar o aspecto da dominação do centro do debate, o autor continua dando destaque a nova configuração da riqueza via instrumentos financeiros, pois, segundo ele, o que diferencia esta fase do capitalismo "[...] que se inicia ao final do século XIX reside na magnitude relativa do que Hilferding denomina de capital financeiro. Ou seja, a partir do momento em que uma parte substantiva da riqueza privada é constituída por títulos negociáveis e prontamente conversíveis em dinheiro" (PINTO, 1994, p. 73). Para o autor, "[...] o sentido mais abstrato da contribuição de Hilferding" passa pelo processo de financiamento das sociedades por ações, em que a viabilidade das transações de compra e venda de títulos via bolsas de valores possibilita a "pronta possibilidade de reconversão do capital em dinheiro". Sem ela, inviabiliza-se a existência do capital financeiro.

Por esta forma, ao analisar a fusão do capital bancário e produtivo, sugere que o principal é "[...] a análise do seu movimento principal: a liquefação dos haveres capitalistas - da riqueza privada. Não se trata [...] de uma fusão entre banco e indústria, mas antes de uma combinação dos atributos dos capitais bancário (liquidez) e industrial (valorização)" (PINTO, 1994, p. 75). Acrescenta que as leituras superficiais feitas por diversos autores acabaram por privilegiar peculiaridades históricas em contraposição a um entendimento mais abstrato e geral aqui apresentado, onde se "[...] pretende refletir a subordina- 


\section{temporolis}

ção da riqueza privada aos mercados financeiros 'em geral'." (PINTO, 1997, p. 25). Tal noção mais ampliada do capital financeiro

[...] parece muito mais adequada para compreender o que há de essencial no capitalismo moderno: a transformação da riqueza privada - de haveres produtivos em títulos negociáveis - através da expansão da grande sociedade por ações em substituição à empresa familiar [...]. Nessa nova etapa não é na firma (enquanto unidade produtiva) que se deve buscar o centro decisório do processo de alocação dos recursos produtivos. É no mercado financeiro - onde se negociam os títulos/ações que compõem a maior parte da riqueza privada - que se situa o fulcro das decisões de investimento e, portanto, de acumulação de capital (PINTO, 1997, p. 24).

Ao mesmo tempo, Guillén (2011a, 2011b) acrescenta outros elementos que são importantes tanto para uma melhor contextualização do termo capital financeiro quanto para uma reflexão sobre o sentido de continuar ou não o utilizando como referência para o entendimento do capitalismo contemporâneo. Da mesma forma que Pinto, o autor diz que o debate sobre a dominação dos bancos sobre a indústria é enganoso e obscurece o essencial da contribuição de Hilferding, "[...] impedindo uma leitura mais cuidadosa do próprio Hilferding que outorga à categoria de capital financeiro [...] um significado mais profundo." (GUILLÉN, 2011a, p. 2-3).

Este significado mais profundo reflete dois elementos centrais: primeiro, que o capital financeiro é o resultado do processo de concentração e centralização do capital e do surgimento das sociedades anônimas e, segundo, que estas implicam não somente a separação da propriedade e o controle da empresa mas, mais importante, "[...] o controle por parte do capital financeiro da emissão e propriedade do capital fictício, quer dizer aquele capital em forma de ações, debêntures e qualquer tipo de títulos financeiros que como brilhantemente havia intuído Marx duplica o capital real investido na produção." (GUILLÉN, 2011b, p. 49).

Ao citar Hilferding, Guillén (2011b, p. 4) afirma que

[...] o capital financeiro é um novo segmento do capital, não o velho capital bancário a serviço da indústria. O que surge desta fusão do capital bancário e o capital industrial é uma nova fração da burguesia: a oligarquia 


\section{temporollis}

financeira que domina não somente as ações, senão que determina, também, o modus operandi da esfera produtiva da economia. Essa oligarquia financeira se apropria da mais-valia social por mecanismos financeiros novos que antes não estavam em mãos das distintas frações separadas do capital. É por isso que a dicotomia entre economia real e economia financeira como esferas separadas da economia é totalmente falsa. (Grifo do autor).

Mesmo que não tenha desenvolvido extensamente seus princípios, o que nos chamou mais atenção foi a referência direta ao capital fictício, chegando a fazer uma pequena relação entre capital fictício, dividendos e lucro de fundador.

Todas estas ideias descritas pelos autores da visão alternativa trazem para o debate elementos novos e importantes, o que de certa forma os diferencia dos demais. Apesar disso, é de se registrar que não achamos que as outras visões estejam equivocadas ou que sejam enganosas no que se refere à interpretação do conceito de capital financeiro. Isso, devido ao caráter ambíguo da leitura de Hilferding. É o que demonstraremos no próximo item.

\section{Avançando no debate sobre o capital financeiro}

Destacaremos neste item três pontos que interferem na discussão envolvendo o capital financeiro: i) a aparente ambiguidade conceitual existente na obra de Hilferding; ii) a insuficiência da perspectiva dialética no entendimento das esferas real e financeira do capital, base da autonomização das formas funcionais do capital; iii) e algumas breves observações acerca das visões anteriormente descritas sobre o capital financeiro. Antes de tudo, concordando com Harvey (1990), Klagsbrunn (1992) e Germer (1995), achamos importante afirmar que não existe o conceito de capital financeiro em Marx, apesar de a tradução francesa de "O Capital" constar a expressão".

5 Para Klagsbrunn (1992, p. 603), "na edição de O Capital da Editora Civilização Brasileira, essa função específica foi traduzida como "capital financeiro", expressão que pouco tem a ver com a original Geldhandlungskapital, tanto em termos literais quanto em conteúdo (...). Ao que tudo indica, a origem do erro está na tradução francesa da Editions Sociales, Paris, 1976, (tradução de Mm Cohen-Solal e M. Gilbert Badia), na qual o título do cap. 19, p. 301, aparece como Le Capital Financier (Capital Marchant)", no lugar de Capital de Comércio de Dinheiro. 


\section{tempordilis}

\subsection{Sobre a ambiguidade em Hilferding}

A despeito da enorme contribuição científica, a leitura de Hilferding sobre o conceito de capital financeiro nos parece ambígua, aparentemente contraditória. ${ }^{6}$ Tanto em Hilferding quanto nos autores que o discute, a existência de íntima relação entre produção e esfera financeira é clara sendo desnecessário novamente resgatá-la. $\mathrm{Na}$ verdade, tal relacionamento faz parte mesmo do esteio de suas interpretações, nas quais as esferas real e financeira se entrelaçam com o desenvolvimento das sociedades anônimas, com a monopolização da indústria e o poder do controle monetário pelos bancos, emprestadores creditícios de primeira instância ao capital produtivo. Neste sentido, verifica-se a junção entre as duas fases do ciclo global do capital industrial, coexistindo com o intuito da expansão e valorização capitalista.

Se, por um lado, não existe qualquer dúvida em relação a estes indícios, por outro, na segunda parte de sua obra, intitulada "A mobilização do capital. O capital fictício", o autor discute temas que se relacionam mais aos aspectos especulativos do capital, dando a impressão de que avançaria na definição inicialmente adotada, acerca da visão tradicional. E os temas tratados, como o capital fictício, são categorias que, em Marx, mostram um caráter mais fetichista, desenvolvidas em um contexto de autonomização, em um grau extremamente reificado.

Acontece que em Hilferding os pontos relacionados à estrutura e compreensão do capital fictício são analisados sobretudo em sua forma concreta, pautados nos tipos de títulos e nos movimentos das bolsas de valores. Apesar de importante, o grau de abstração necessário para a compreensão destas categorias não aparece no centro da discussão. Não fica claro, por exemplo, que o caráter fictício do capital se autonomiza no ciclo global, e que, ao mesmo tempo, mantém a sua dependência em relação ao capital produtivo. O caráter dialético desta percepção nos parece secundário, quiçá inexistente, sobretudo quanto à teoria do valor-trabalho de Marx.

Mollo (1989, p. 163) afirma que "Rudolf Hilferding foi o autor que, na tradição marxista, analisou mais profundamente a ideia do

6 Fomos percebendo que esta opinião também é compartilhada por autores como Harvey (1990), Pinto (1994) e Germer (1995). 


\section{temporollis}

capital fictício"; ao mesmo tempo, a autora afirma que "[...] mesmo fiel a Marx, Hilferding não presta atenção a certos aspectos que consideramos importante quando se trata de analisar o capital fictício", sendo um desses "[...] que Hilferding não relativiza a autonomia da circulação em relação à produção” (MOLLO, 1989, p. 209), afirmação esta central no nosso entendimento.

Certamente Hilferding contribuiu decisivamente para a compreensão e utilização da categoria capital fictício de Marx, analisando, por exemplo, o desenvolvimento do dinheiro de crédito. A primeira parte de seu livro, intitulada "Dinheiro e Crédito", muito criticada na literatura econômica, já coloca no debate categorias fundamentais para a formação do capitalismo, sob a base do crescimento do sistema de crédito. Ao analisar a substituição gradativa do dinheiro como moeda fiduciária e como "[...] o crédito se apresenta de imediato como simples resultado da função alterada do dinheiro como meio de pagamento" (HILFERDING, 1985, p. 85), o autor gradativamente vai fazendo aparecer o crédito de circulação em substituição ao dinheiro, o que "poupa o dispendioso metal, visto significar a transferência de mercadorias sem a intervenção do dinheiro." (HILFERDING, 1985, p. 86).

Os bancos neste sentido desempenham a função vital de fazê-los circular, além da função de compensação, crescendo assim a economia monetária já que os títulos tornam-se meios de pagamento. "O banqueiro substitui o crédito comercial pelo crédito bancário trocando as notas promissórias por notas bancárias, ou seja, as duplicatas industriais e comerciais por suas próprias promissórias." (HILFERDING, 1985, p. 87).

A transformação do sistema bancário, o aparecimento do crédito bancário e a diminuição do capital monetário à disposição dos capitalistas industriais aumentam a capacidade de circulação do dinheiro de crédito pelos bancos, rompendo as barreiras da produção. Assim, "[...] se o crédito de circulação exerce a função de substitutivo de moeda corrente, o crédito que converte qualquer tipo de dinheiro ocioso (moeda corrente ou fiduciária) em capital monetário ativo pode ser chamado de crédito de capital (ou de investimento) [...]", afirma Hilferding (1985, p. 90).

Todas estas breves palavras introduzem categorias fundamentais da análise marxista que caracterizam o dinheiro de crédito, mul- 


\section{temporalis}

tiplicando assim as formas "ilusórias" e "fictícias" do capital. Como afirma Marx (1985, p. 15), "[...] nesse sistema de crédito tudo se duplica e triplica e se transforma em mera quimera [...]”, algo mesmo fantasmagórico.

Ao discutir a bolsa de valores, de mercadorias, o capital bancário, a atividade emissora, Hilferding manteve-se atento para a negociação dos títulos e ações como forma de financiamento das sociedades anônimas, como um mecanismo de captação de recursos para o financiamento da atividade produtiva, recurso este que também guarda relação direta com o movimento especulativo. Como o próprio autor diz, "[...] o título em especulação está propriamente em contínua circulação na bolsa. É um vaivém circular e não linear." (HILFERDING, 1985, p. 139).

É verdade também que Hilferding avança e aparentemente nega Marx ao tratar do conceito de "lucro diferencial", importante definição que indica ganhos financeiros advindos sem a contrapartida da criação de riqueza real, produtiva, da apropriação da mais-valia.? Ao fazer isto, o autor aponta, mas ao mesmo tempo não desenvolve teoricamente, a desvinculação entre o real e o financeiro em um nível mais reificado do capital fictício, o que se requer para isso um processo de compreensão da natureza autonomizada do capital a partir de suas formas funcionais.

Então, o que nos chama a atenção é o fato de que ao mesmo tempo em que o autor trata em seus parágrafos conceituais da relação banco e indústria e seu aspecto de dominação, anuncia por outro a inserção e discussão do capital fictício como categoria central do capital financeiro. Mas, ao que parece, esta última discussão não avança, não aparece de forma mais profunda, não anuncia o processo de autonomização relativa da esfera da circulação, passo esse que consideramos importante, funcional e mesmo contraditório para o capital. Evidentemente, fazemos essas observações sempre lembrando o período histórico vivido pelo autor, fato este que, se não impossibilita, ao menos dificulta a percepção da dinâmica especulativa do capitalismo. $^{8}$

7 Para maiores informações, conferir Sabadini (2015).

8 Deve-se destacar também que "O capital financeiro" de Hilferding foi publicado apenas 16 anos após o Livro III de "O Capital" de Marx, livro este que analisa, dentre outros, as formas bancárias, o capital a juros, o crédito e o capital fictício. 


\section{temporollis}

Resumindo: a aparente ambiguidade do conceito de capital financeiro reside, então, no fato de que ao mesmo tempo em que se dá destaque à relação banco e indústria, importante para a compreensão da dinâmica do capital, indica, por outro, a centralidade temática da esfera financeira pela via do dinheiro de crédito e do capital bancário, fictício. Assim, suas indicações conceituais podem ganhar vários sentidos, como demonstrados anteriormente. Adicionalmente, sugerimos que não há um avanço teórico quanto à compreensão do processo de substantivação do valor e das formas funcionais do capital.

Esta "imprecisão" nos levou, em determinado momento, a seguinte indagação: a aparente ambiguidade em Hilferding sugere em seus escritos uma insuficiência da teoria do valor-trabalho de Marx? Talvez sim. Temos, por enquanto, apenas intuições que necessitam ser amadurecidas. ${ }^{9}$ Talvez a ênfase de Hilferding na mutação da propriedade tenha colocado em segundo plano dois aspectos centrais: 0 caráter contraditório que as formas financeiras assumem ao se descolarem das atividades reais e, principalmente, a relação existente entre as frações do capital quanto à produção, apropriação e transferência de riqueza.

Então, a ideia de associação, subordinação ou outra expressa pelas visões sobre o capital financeiro não é suficiente para explicar a dinâmica que muitas vezes é atribuída ao seu conceito, sobretudo ao analisarmos o capitalismo contemporâneo. Da forma como é tratada, tal definição se aproxima daquela de capital a juros em Marx, que, do ponto de vista da totalidade do ciclo global, tem base real, produtiva, enquanto a dinâmica fictícia, especulativa, exige a nosso ver o entendimento da natureza da desmaterialização do dinheiro sob a forma do capital fictício, sustentando-se "pela autonomização das formas funcionais do capital”.

9 Citamos aqui algumas delas: i) sua interpretação acerca da teoria do dinheiro em Marx, bastante criticada por vários autores, dá indícios dessa insuficiência; ii) o privilégio à troca como ato de coesão social, de coerência da análise econômica em que "as pessoas são, assim, proprietários particulares que, por meio do desenvolvimento da divisão do trabalho, são obrigados a entrar em relação uns com os outros. Esse ato [da troca] se concretiza na troca de seus produtos. É a partir desse ato que se estabelece a coesão da sociedade atomizada pela propriedade privada e pela divisão do trabalho" (HILFERDING, 1985, p. 33); iii) o não aparecimento do dinheiro de crédito assumindo formas cada vez mais autonomizadas, fictícias. 


\subsection{Sobre a autonomização das formas funcionais do capital}

Indicaremos, sucintamente, alguns pontos. ${ }^{10} \mathrm{~A}$ partir das noções de valor e capital e das mutações das formas do valor, o sistema capitalista se transforma com vistas à valorização do valor, alterando e acelerando as fases e a rotação do capital. O sentido do movimento passa a ser uma constante na constituição do sistema capitalista, fazendo-o evoluir, alterando-se e sempre buscando o novo. Ao passar de uma forma a outra, ao assumir formas diferenciadas de mercadoria, de dinheiro, revelando-se um "ser" que existe por si mesmo, o valor, num processo histórico e dialético de desenvolvimento, se substantiva tornando-se valor-capital. É nesta perspectiva de percorrer "diferentes formas", "diferentes movimentos", que devemos entender a dinâmica das fases da produção e da circulação, dando origem às "formas funcionais do capital".

Apresentadas em partes isoladas no Livro II de "O Capital", a rotação e circulação do capital aparecem sob a forma inicial de capital dinheiro, de capital produtivo e de capital mercadoria que, apesar de parecem autônomas, expressam a totalidade do ciclo. Cada fase do ciclo do capital industrial $\left(D_{1}-M-D_{2}\right)$ possui funções específicas na tentativa da concretização final do ato de compra e venda das mercadorias, em que o capitalista, seja na esfera da produção ou nas duas etapas da circulação, $D_{1}$ e $D_{2}$ atua diretamente. Ao passar de um momento no qual um só capitalista ocupava as três funções acima descritas, para outro, no qual cada capitalista se especializa em uma das formas funcionais, num contexto de divisão das funções, se estabelece desta forma a "autonomização das formas funcionais do capital", representando mais fielmente o funcionamento de um sistema capitalista mais desenvolvido.

Assim, as formas iniciais do capital se alteram, evoluem para outras formas mais mistificadas, mais desenvolvidas do valor. Aparecem o capital comercial, posteriormente o capital de comércio de mercadorias, o capital de comércio de dinheiro, o capital a juros e em seu grau mais extremo de mistificação, o capital fictício.

Neste processo, o capital fictício faz com que o proprietário do capital tenha uma remuneração sem contrapartida em capital produtivo. Tal característica dissimula ainda mais as conexões com o

10 Detalhes podem ser consultados em Carcanholo e Sabadini (2011) e Sabadini (2013). 


\section{temporollis}

processo real de valorização do capital, consolidando a imagem de um capital independente, que se valoriza por si mesmo nos mercados de compra e venda especulativos. Como diz Marx (1985), ao final do processo não existe nenhum traço de relação com o processo real de valorização do capital e a ideia de um capital autônomo, capaz de criar valor por ele mesmo, é intensificada.

Aqui, a substantivação do valor-capital e a desmaterialização do dinheiro assumem um movimento ainda mais autonomizado na constituição do sistema monetário e financeiro. Assim, o capital fictício é real e irreal ao mesmo tempo. Na aparência, é real em relação ao ato individual de cada capitalista, que recebe remuneração sob a forma de juros ou lucro; na essência, na perspectiva da totalidade, é real e fictício ao mesmo tempo, pois não tem substância do valor-trabalho, se multiplicando a partir do movimento especulativo.

Se autonomizando, ultrapassando em volume as fronteiras dos limites suportáveis pela reprodução do capital industrial, o capital fictício demonstra ter um movimento "independente", interferindo na trajetória da acumulação capitalista. Por estes traços, a complexificação e a autonomização do esquema de reprodução capitalista continuam em um grau ainda mais sofisticado que aquele ligado mais diretamente a esfera produtiva, como o capital a juros. Tomando-se por base estes elementos, acreditamos que a "autonomia relativa" da esfera financeira parece não ocupar um lugar de destaque em Hilferding, ao menos no sentido das mutações das formas do valor, o que compromete parte de seu conceito de capital financeiro, sobretudo aquele que trata dos aspectos eminentemente fictícios, especulativos, do ciclo global do capital.

\subsection{Sobre as visões conceituais}

Quando observamos as visões conceituais anteriormente descritas, temos a presunção de que todas as três estão corretas, cada uma à sua forma, ao menos no sentido de enfatizarem ou não aspectos que o próprio Hilferding descreveu. De fato, não estamos totalmente de acordo com nenhuma delas e concordamos com todas ao mesmo tempo, pois cada uma, em função da ambiguidade aqui sugerida, se baseia nas afirmações do próprio autor. Assim, não adotamos e nem criamos um conceito de capital financeiro; preferimos seguir as categorias do próprio Marx que descreve muito bem as várias formas de se entender as relações de submissão, de convergência e de auto- 
nomia entre as fases da produção e da circulação capitalista.

Se concordarmos com a visão tradicional, é de se destacar, como fazem as visões intermediária e alternativa, que ela não frisa os aspectos fictícios, especulativos, minimizando-os de certa forma. Já nas visões intermediária e alternativa, mais ecléticas por natureza e certamente mais abrangentes, analisam-se aspectos importantes como a ênfase a não separação entre as esferas real e financeira e os aspectos fictícios do capital. Mas, ao mesmo tempo, a crítica feita à visão tradicional pelo seu reducionismo conceitual peca a nosso ver, pois, como indicamos anteriormente, várias são as indicações do próprio Hilferding que sustentam esta interpretação.

Quanto à dominação econômica pelo capital bancário, seu questionamento ultrapassa a comprovação de maiores taxas de lucro setoriais, apesar de encontrarmos várias pistas para essa constatação empírica. " É verdade que existem limites ao cálculo das taxas de lucro em cada fase, sendo talvez mesmo impossível de se indicar números precisos de sua participação no capital global. Mas, isto não implica dizer a impossibilidade de demonstrar sua evolução, sua tendência, bem como o grau de crescimento relativo da esfera financeira.

\section{Considerações finais}

A etimologia da palavra financeiro é muito clara: o que se diz "referente a finanças". Isto por si só é suficiente para caracterizar o conceito de capital financeiro em qualquer aspecto relacionado aos movimentos financeiros ao redor do mundo, quer sejam especulativos ou não, quer estejam ligados ou não a produção. Neste sentido, o termo pode representar genericamente a finança contemporânea, o mercado financeiro, a relação banco e indústria, os investidores institucionais (fundos de pensão, especulativos). Porém, o rigor teórico nos induziu a melhor qualificar o debate em torno desta definição que

11 Pinto (1994, p. 66) sugere que “[...] como aqui a noção de hegemonia ou dominação de um setor está restrita a sua expressão econômica mais concreta (rentabilidade substancialmente acima da média), pode-se afirmar que não há, até onde se saiba, qualquer evidência empírica que permita sustentar essa hipótese." Apesar de esta afirmação ser de meados da década de 1990, período ainda de crescimento dos ativos especulativos, encontramos em vários autores, como Duménil e Lévy (2004), Husson (2006, 2007), Morin (2006), Gonçalves (2006), Marquetti et al. (2007), Sabadini (2008), dentre outros, informações qualitativas e quantitativas recentes sobre o crescente peso relativo da esfera financeira do capital, bem como a evolução e diferença entre a taxa de lucro industrial e bancária. 


\section{temporalis}

é utilizada, na maior parte das vezes, de maneira indiscriminada para caracterizar o capitalismo contemporâneo.

E para isso, impossível seria a nossa tarefa sem passar pela leitura de Hilferding que trata da influência do capital financeiro em várias temáticas, como a oligopolização, os ciclos econômicos, a crise, o imperialismo. Sua importância na literatura acadêmica é indiscutível, sobretudo quanto ao desdobramento das categorias centrais discutidas no Livro I de "O Capital" que se concretizam no livro III, colocando no centro do debate, e em pleno fim de século XIX e início do século $\mathrm{XX}$, categorias marxistas que ainda hoje são pouco conhecidas.

Nosso objetivo aqui não era forjar outro conceito para incorporá-lo aos demais e muito menos fazer a crítica sem as mediações históricas e teóricas necessárias. Cumpre apreender que talvez mais importante que isto seja a absorção de suas contribuições para compreender o capitalismo contemporâneo, se apropriando de seus pontos positivos e negativos e revalorizando seus aportes para entender a dinâmica capitalista atual.

Hilferding estava totalmente correto ao verificar a face financeira do capitalismo de sua época. Mas, a ambiguidade de seu conceito de capital financeiro gerou interpretações diferenciadas sobre o mesmo, o que nos sugeriu afirmar que todas as visões aqui apresentadas são corretas, não significando dizer suficientes para entender a dinâmica do capitalismo contemporâneo.

\section{Referências}

CARCANHOLO, Reinaldo A.; SABADINI, Mauricio de S. Sobre o capital e a mais-valia. In: - (Org.). Capital: essência e aparência. São Paulo: Expressão Popular, 2011. v. 1.

DELILEZ, Jean-Pierre. Accumulation, capital financier, monopolisme. Révue économique, v. 21, n. 5, p. 799-827, 1970.

DUMENIL, Gérard. ; LÉVY, Dominique. Le néolibéralisme sous hégémonie états-unienne. La finance mondialisée: racines sociales et politiques, configuration, conséquences. Paris: Éditions la Découverte, 2004.

GERMER, Claus M. Dinheiro, capital e dinheiro de crédito: o dinheiro segundo Marx. 1995. 278 f. Tese (Doutorado em Economia)- Universi- 
dade Estadual de Campinas, Campinas, 1995.

GONÇALVES, Reinaldo. A dominação do capital financeiro no Brasil. Revista da Sociedade Brasileira de Economia Política, Rio de Janeiro, n. 19, p. 25-43, 2006.

GUILLÉN, Arturo. La notion des capital financiero em Hilferding y su importância para la comprensión des capitalismo contemporâneo. Análisis, n. 8, p. 1-7, enero-abril $2011 a$.

. Claves para el análisis del capitalismo contemporâneo. Análisis, n. 8, p. 46-54, enero-abril 2011b.

HARVEY, David. Los límites del capitalismo y la teoría marxista. México: Fondo de Cultura Econômica, 1990.

HILFERDING, Rudolf. O capital financeiro. São Paulo: Nova Cultural, 1985.

HUSSON, Michel. Finance, hyper-concurrence et reproduction du capital. La finance capitaliste. Paris: Presses Universitaires de France, 2006.

. La baisse tendancielle de la part salariale. 2007. Disponível em: <http://hussonet.free.fr/parvabis.pdf>_Acesso em: 21 mar. 2015.

KLAGSBRUNN, Vitor $\mathrm{H}$. Considerações sobre a categoria dinheiro de crédito. Ensaios FEE, Porto Alegre, v. 13, n. 2, p. 592-615, 1992.

LAPAVITSAS, Costas. Financialised capitalism: direct exploitation and periodic bubbles. 2008. (Mimeo). Disponível em: <http://www.leftlibrary.com/lapavitsas1.pdf >. Acesso em: 8 fev.2012.

LÊNIN, Vladimir I. Imperialismo, fase superior do capitalismo. São Paulo: Global, 1979.

MARQUETTI, Adalmi; MALDONADO FILHO, Eduardo; LAUTERT, Vladimir. The rate of profit in the brazilian economy, 1953-2003. In. CONGRÈS MARX INTERNATIONAL, 5, Université de Paris X Nanterre, 2007. Actes... Paris, 2007. Disponível em: <http://netx.u-paris10.fr/actuelmarx/cm5/index5.htm> Acesso em; 20 dez. 2012.

MARX, Karl. O capital. São Paulo: Abril Cultural, 1984. V. III, Tomo I. 


\section{tempordilis}

. O capital. São Paulo: Abril Cultural, 1985. V. III, Tomo II.

MOLLO, Maria de Lourdes Rollemberg. Monnaie, valeur et capital fictif. 1989. Tese (Doutorado em Economia)- Université Paris X, Nanterre, 1989.

MORIN, François. Le nouveau mur de l'argent: un essai sur la finance globalisée. Paris: Éditions Seuil, 2006.

PALLOIX, Christian. Rudolf Hilferding: des avances novatrices. Cahiers d'économie politique, n. 51, p. 265-285, 2006.

PIERRE, Matari. El capital financiero de Hilferding: legado y lecciones para el análisis contemporáneo. Memoria, n· 246, p. 40-47, sept. 2010. Disponível em: <http://www.academia.edu/7989575/El_Capital_financiero_de_Hilferding_centenario>Acesso em: 19 jul. 2011.

PINTO, Nelson Prado A. O capital financeiro na economia contemporânea: uma revisão teórica e histórica de seu papel no desenvolvimento recente dos Estados Unidos. 1994. 172 f. Tese (Doutorado em Economia)- Universidade Estadual de Campinas, Campinas, 1994.

. O capitalismo financeiro. Crítica Marxista, São Carlos, v. 1, t. 5, p. 9-26, 1997.

SABADINI, Mauricio de Souza. Le capital fictif et ses effets sur la macroéconomie et sur le monde du travail au Brésil. Tese (Doutorado em, Université Paris 1 - Panthéon Sorbonne, Centre d'Économie de la Sorbonne (CES), 2008. Disponível em: <https://tel.archives-ouvertes. fr/tel-00354467/en/> Acesso em: 27 abr. 2012.

- Especulação financeira e capitalismo contemporâneo: uma proposição teórica a partir de Marx. Economia e Sociedade, Campinas, v. 22, n. 3 (49), p. 583-608, dez. 2013.

. O capital fictício e suas formas: lucros de fundador, diferencial e fictício. In: GOMES, Helder (Org.). Especulação e lucros fictícios: formas parasitárias da acumulação contemporânea. São Paulo: Outras Expressões, 2015.

SWEEZY, Paul. Teoria do desenvolvimento capitalista: princípios de economia política marxista. São Paulo: Abril Cultural, 1983. 